\title{
Effect of an intervention to improve the cardiovascular health of family members of patients with coronary artery disease: a randomized trial
}

Robert D. Reid PhD MBA, Lisa A. McDonnell MSc, Dana L. Riley PhD, Amy E. Mark PhD, Lori Mosca MD PhD, Louise Beaton MSc, Sophia Papadakis PhD MHA, Chris M. Blanchard PhD, Heidi Mochari-Greenberger PhD RD, Patricia O'Farrell RN, George A. Wells PhD, Monika E. Slovinec D'Angelo PhD, Andrew L. Pipe MD

\begin{abstract}
- Abstract
Background: Family members of patients with coronary artery disease (CAD) have higher risk of vascular events. We conducted a trial to determine if a family heart-health intervention could reduce their risk of CAD.

Methods: We assessed coronary risk factors and randomized 426 family members of patients with CAD to a family heart-health intervention ( $n=211)$ or control $(n=215)$. The intervention included feedback about risk factors, assistance with goal setting and counselling from health educators for 12 months. Reports were sent to the primary care physicians of patients whose lipid levels and blood pressure exceeded threshold values. All participants received printed materials about smoking cessation, healthy eating, weight management and physical activity; the control group received only these materials. The main outcomes (ratio of total cholesterol to high-density lipoprotein [HDL] cholesterol; physical activity; fruit and vegetable consumption) were assessed at 3 and 12 months. We examined group and time effects using mixed models analyses with the baseline values as covariates. The secondary outcomes were plasma lipid levels (total cholesterol, low-density lipoprotein cholesterol, HDL cholesterol and triglycerides); glucose

level; blood pressure; smoking status; waist circumference; body mass index; and the use of blood pressure, lipid-lowering and smoking cessation medications.

Results: We found no effect of the intervention on the ratio of total cholesterol to HDL cholesterol. However, participants in the intervention group reported consuming more fruit and vegetables (1.2 servings per day more after $3 \mathrm{mo}$ and 0.8 servings at $12 \mathrm{mo} ; p<0.001$ ). There was a significant group by time interaction for physical activity $(p=0.03)$. At 3 months, those in the intervention group reported 65.8 more minutes of physical activity per week ( $95 \%$ confidence interval [Cl] 47.0-84.7 min). At 12 months, participants in the intervention group reported 23.9 more minutes each week ( $95 \% \mathrm{Cl} 3.9-44.0 \mathrm{~min})$.

Interpretation: A health educator-led hearthealth intervention did not improve the ratio of total cholesterol to HDL cholesterol but did increase reported physical activity and fruit and vegetable consumption among family members of patients with CAD. Hospitalization of a spouse, sibling or parent is an opportunity to improve cardiovascular health among other family members. Trial registration: clinicaltrials.gov, no NCT00552591.
\end{abstract}

$\mathrm{P}$ eople with a family history of coronary artery disease (CAD) among their firstdegree relatives have an increased risk of vascular events..$^{1-5}$ This risk is greater if more than 1 relative has heart disease, or if the onset of disease in relatives occurred before age $55 .^{1-3,5} \mathrm{~A}$ concordance of coronary risk factors between patients with heart disease and their spouses has also been reported..$^{6-10}$ Although genetic factors are important, familial aggregation of coronary risk factors also plays a role. ${ }^{9,11,12}$ Guidelines recommend screening individuals with a positive family history, ${ }^{13-15}$ but screening rates are low $(<15 \%)$, and interventions are rarely initiated. ${ }^{16,17}$ Family members of patients with heart disease may benefit from focused interventions to improve cardiovascular health. Counselling that address physical inactivity and dietary behaviours is central to these interventions; clinical management of risk factors such as tobacco addiction, dyslipidemia, hypertension and dysglycemia are also important. We developed and evaluated a year-long family-based heart-health intervention for the siblings, offspring and spouses of patients admitted to hospital with an acute coronary event.
Competing interests:

Robert Reid has received speaker's fees from Pfizer for smoking cessation. Andrew Pipe has received grant funding and persona fees from Pfizer, personal and nonfinancial support from Johnson \& Johnson, and personal fees from GlaxoSmithKline and Amgen. No competing interests declared by Lisa McDonnell, Dana Riley, Amy Mark, Lori Mosca, Louise Beaton, Sophia Papadakis, Chris Blanchard, Heidi Mochari-

Greenberger, Patricia O'Farrell, George Wells or Monika Slovinec D'Angelo.

Disclaimer: George Wells is a biostatistical consultant for $C M A J$ and was not involved in the editorial decision-making process for this article.

This article has been peer reviewed.

Correspondence to: Robert D. Reid, breid@ottawaheart.ca

CMAJ 2014. DOI:10.1503 /cmaj.130550 


\section{Methods}

\section{Study design and participants}

We conducted a 12-month randomized trial at the University of Ottawa Heart Institute, a tertiary care cardiac centre. We recruited participants using advertisements and flyers distributed to patients and family members. Potential participants attended a screening visit that assessed their coronary risk factors. Siblings, children and spouses of patients with $\mathrm{CAD}$ who had at least 1 modifiable risk factor (i.e., smoking, physical inactivity, dyslipidemia, hypertension or abdominal obesity) were eligible. We excluded people with one of the following conditions: established coronary, cerebrovascular or peripheral vascular disease; diabetes; current or planned pregnancy; or fasting blood glucose $\geq 7 \mathrm{mmol} / \mathrm{L}$ at screening. We limited participation to 1 family member per index patient.

The University of Ottawa Heart Institute Research Ethics Board approved the study, and participants provided written informed consent.

\section{Randomization}

We used a computer-generated sequence to implement stratified randomization based on relation to the index patient (sibling, child or spouse) with 1:1 allocation. Allocations to the heart-health intervention or the control group were contained in sealed, numbered envelopes; the study coordinator assigned participants once eligibility was confirmed by baseline screening. Study staff included a research coordinator (notified participants of treatment allocation and provided care to those in the control group) and 2 health educators who were not blinded to treatment allocation. Health educators provided counselling to those in the intervention group. Two research assistants (unaware of allocation) performed all assessments.

\section{Procedures}

Risk factors were assessed at baseline, 3 months and 12 months. Fasting blood samples were collected, and plasma lipid and glucose levels were analyzed by the Ottawa Hospital laboratory. Blood pressure was measured using an automated blood pressure monitor (BPTru Medical Devices). Height, weight and waist circumference were measured, and body mass index was calculated. Selfreported smoking status was verified ${ }^{18}$ using a carbon monoxide analyzer (Bedfont Scientific). Dietary patterns were measured by use of a foodfrequency questionnaire..$^{19}$ Levels of physical activity (moderate or vigorous) were measured using a modified Godin Leisure-Time Exercise Questionnaire. ${ }^{20}$ Participants were asked to bring any medications that they were taking to the assessments; the names and dosages were recorded.

\section{Intervention}

The heart-health intervention included feedback about the results of the baseline and 3-month assessments; goal setting; 17 counselling sessions with a trained health educator; and the communication of reports and recommendations to the participant's primary care physician. Counselling sessions occurred weekly for the first 12 weeks and then at weeks 16, 20, 26, 39 and 52. The first 2 sessions lasted 45 minutes, and the remaining sessions lasted 15-20 minutes. The second counselling session (at week 2) was face-to-face; all others were by telephone. The counselling scripts (available from the corresponding author) were standardized. The health educators received 2 days of training about the counselling and were periodically observed by an experienced therapist, who provided feedback about their performance.

During the sessions in weeks 1 and 2, participants received feedback about their risk levels relative to recommendations. ${ }^{13,21-24}$ The health educators helped participants set goals for reducing their risk and create action plans. An assessment summary and indications for his or her medical care were mailed to the patient's primary care physician. Medical care was suggested if the patient's blood pressure or lipid levels exceeded threshold values (i.e., blood pressure $140 / 90 \mathrm{~mm} \mathrm{Hg},{ }^{21}$ low-density lipoprotein $[\mathrm{LDL}]$ cholesterol $>2.0 \mathrm{mmol} / \mathrm{L}$ if participant's Framingham Risk Score was 20\%, LDL cholesterol $>3.5 \mathrm{mmol} / \mathrm{L}$ if the Framingham Risk Score was $10 \%-19 \%$, or LDL cholesterol $>5.0 \mathrm{mmol} / \mathrm{L}$ if the Framingham Risk Score was $<10 \%){ }^{13}$

Participants received printed materials about smoking cessation, healthy eating, weight management and physical activity. During the phone calls at weeks 3-12 16, 20, 26, 39 and 52, the health educators engaged participants in a dialogue about progress toward their goals and recommended strategies to overcome any barriers. During the week 16 session, participants received the results of their 3-month assessment. The summary of this assessment and recommendations for medical care were mailed to the patient's primary care physician.

The control group received printed materials about smoking cessation, healthy eating, weight management and physical activity. A report was sent to the participant's primary care physician if the critical threshold values for blood pressure or lipids were exceeded.

\section{Outcome measures}

The primary outcomes were the ratio of total cholesterol to high-density lipoprotein (HDL) cholesterol, weekly minutes of moderate and vigorous physical activity, and the number of daily servings of fruits and vegetables consumed. 
The secondary outcomes were plasma lipid levels (total cholesterol, LDL cholesterol, HDL cholesterol and triglycerides); glucose level; blood pressure; smoking status; waist circumference; body mass index; and the use of blood pressure, lipid-lowering and smoking cessation medications.

We estimated the incremental costs of the intervention based on the amount of time the health educators spent providing counselling and managing participant contacts. We derived the costs by multiplying the quantities of resources used by the unit costs.

\section{Statistical analysis}

We estimated a sample size of 426 participants based on minimal clinically important differences between groups of $10 \%$ for the ratio of total to HDL cholesterol, ${ }^{25} 30$ minutes of moderate to vigorous physical activity per week ${ }^{26}$ and 1 daily serving ${ }^{27}$ of fruits and vegetables, assuming $80 \%$ power and dividing our $\alpha$ value (0.05) by 3 to account for multiple outcomes. Our primary analysis was intention to treat; however, our sample size assumed $30 \%$ loss to follow-up, which allowed a secondary, complete case analysis (data not shown).
We used linear mixed models for repeatedmeasures analyses to evaluate between group differences for all continuous outcomes. We included group by time interaction, and the baseline value of the variable and other variables associated with missing data were included as covariates. We conducted pair-wise comparisons of simple main effects for variables with significant interaction effects to investigate differences at each follow-up time. We used $\chi^{2}$ testing for analyses of between-group differences in smoking cessation and use of blood pressure, lipidlowering and smoking cessation medications. We conducted exploratory analyses to examine the effects after stratification by relationship to the index patient (sibling, offspring or spouse).

Analyses were conducted using SPSS 21.0 (IBM Corporation).

\section{Results}

\section{Participants}

Between 2007 and 2010, we screened 835 individuals. Of these, 457 were eligible, and 426 (93.2\% of eligible people) agreed to participate (Figure 1). Participants were randomly assigned

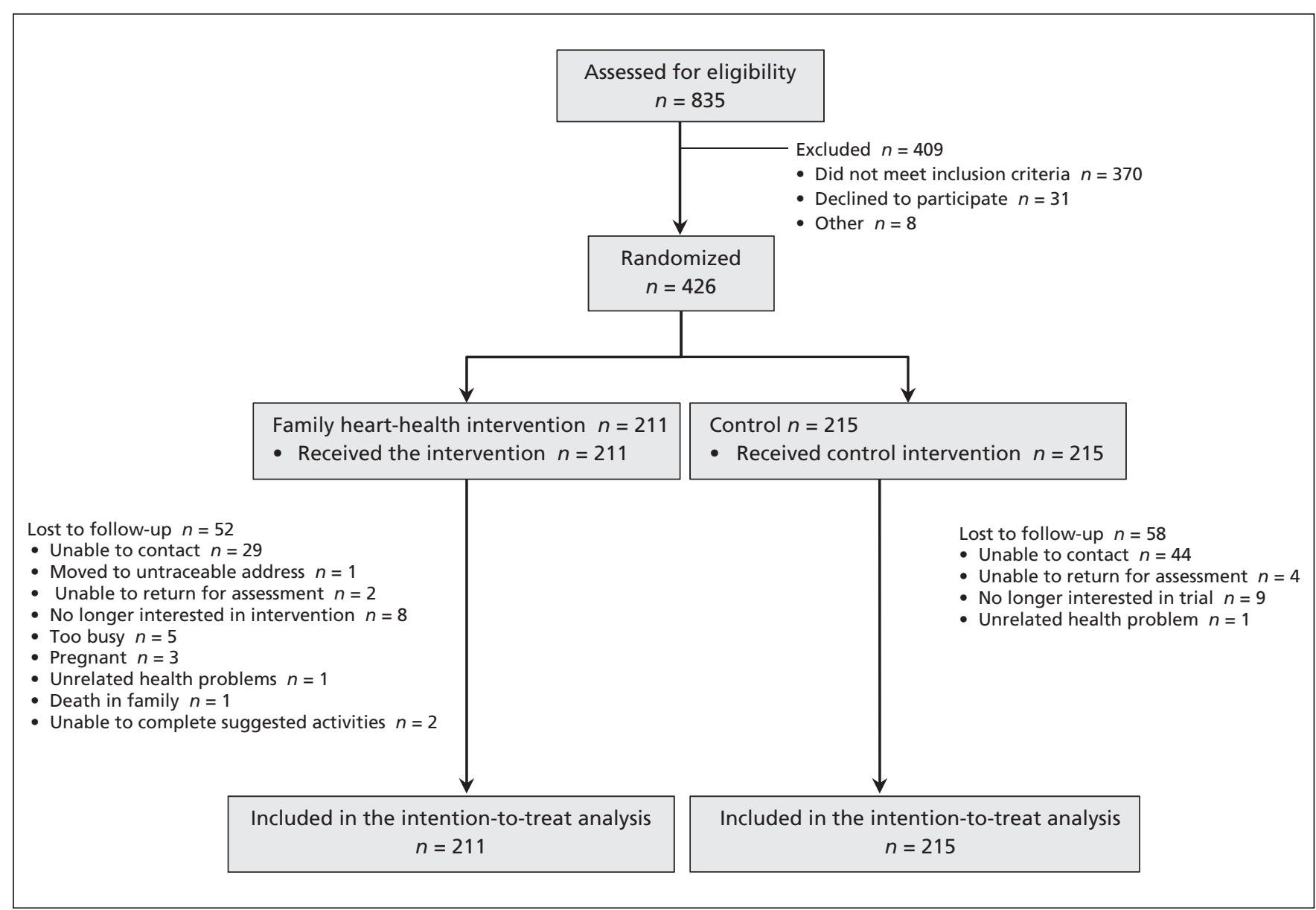

Figure 1: Flow of participants through the trial. 
to the heart-health intervention ( $n=211)$ or control $(n=215)$. In total, data were available for $83.1 \%$ of participants from the 3 -month assessment and $74.2 \%$ of participants from the 12 month assessment, with no differential loss between groups. Participants with missing data were younger $(45.0 \pm 11.5$ v. $51.9 \pm 11.1$ years; $p=0.004)$ and at lower risk of CAD based on the Framingham Risk Score $(5.2 \pm 5.9$ v. $5.9 \pm$ $7.2 \%$ risk; $p=0.02$ ) at baseline. We adjusted for these covariates in our analyses. Baseline characteristics are shown in Table 1. The predicted 10year risk of myocardial infarction or cardiac death based on the Framingham Risk Score was high $(\geq 20 \%)$ in $6.1 \%$ of participants.

\section{Adherence to treatment}

Following baseline assessment, 91 letters with indications for medical care were sent to primary care physicians for patients with blood pressure or lipid values that exceeded the thresholds (46 participants in the intervention group and 45 in the control group). At the 3-month assessment, 27 participants in the intervention group and 25 in the control group reported having an appointment with their physician since the baseline assessment. Following the 3-month assessment, 70 letters were sent to primary care physicians (31 participants in the intervention group and 39 in the control group). At the 12-month assessment, 25 participants in the intervention group and 20 in the control group reported having an appointment with their physician since the 3month assessment. Participants in the intervention group completed a median of 15 of the 17 counselling sessions (range 0-17 sessions; interquartile range 11-17 sessions).

\section{Outcomes}

The effects of the heart-health intervention on continuous outcomes are presented in Table 2.

We found no effect of the intervention on the ratio of total cholesterol to HDL cholesterol; however, those in the intervention group reported consuming more fruits and vegetables $(p<$ $0.001)$. There was a significant group by time interaction for physical activity $(p=0.03)$. At the 3-month assessment, participants in the interven-

Table 1: Baseline characteristics of the trial participants, by group

\begin{tabular}{|c|c|c|c|}
\hline \multirow[b]{2}{*}{ Characteristic } & \multicolumn{3}{|c|}{ Group; no. (\%) or mean \pm SD } \\
\hline & $\begin{array}{c}\text { Family heart-health } \\
\text { intervention } \\
n=211\end{array}$ & $\begin{array}{l}\text { Control } \\
n=215\end{array}$ & $\begin{array}{l}\text { Total } \\
n=426\end{array}$ \\
\hline Age, yr, mean $\pm S D$ & $52.0 \pm 11.9$ & $51.1 \pm 11.3$ & $51.5 \pm 11.6$ \\
\hline Women & $128(60.7)$ & $133(61.9)$ & $261(61.3)$ \\
\hline White & $201(95.3)$ & $205(95.3)$ & $406(95.3)$ \\
\hline Married or living with partner & $164(77.7)$ & $172(80.0)$ & 336 (78.9) \\
\hline Education, yr, mean \pm SD & $14.6 \pm 2.6$ & $14.7 \pm 2.6$ & $14.7 \pm 2.6$ \\
\hline Family history of premature CAD & $96(45.5)$ & $95(44.1)$ & $191(44.8)$ \\
\hline Current daily smoker & $20 \quad(9.5)$ & $19 \quad(8.8)$ & $39 \quad(9.1)$ \\
\hline No family doctor & $9 \quad(4.2)$ & $14 \quad(6.5)$ & $23 \quad(5.4)$ \\
\hline Body mass index $\geq 30$ & $79(37.4)$ & $87(40.5)$ & $166(39.0)$ \\
\hline $\begin{array}{l}\text { Waist circumference }>94 \mathrm{~cm} \text { (men) } \\
\text { or }>80 \mathrm{~cm} \text { (women) }\end{array}$ & $64(30.3)$ & $54(25.1)$ & $118(27.7)$ \\
\hline Lipid-lowering therapy & $42(19.9)$ & $51(23.7)$ & $93(21.8)$ \\
\hline Antihypertensive therapy & $67(31.8)$ & $52(24.2)$ & $119(27.9)$ \\
\hline Smoking cessation pharmacotherapy* & $1(5.0)$ & $2(10.5)$ & $3(7.7)$ \\
\hline \multicolumn{4}{|l|}{ Relation to index patient } \\
\hline Spouse & $67(31.8)$ & $65(30.2)$ & $132(31.0)$ \\
\hline Offspring & $98(46.4)$ & $101(47.0)$ & $199(46.7)$ \\
\hline Sibling & $46(21.8)$ & $49(22.8)$ & $95(22.3)$ \\
\hline $\begin{array}{l}\text { Percent risk of CAD eventt over next } \\
10 \mathrm{yr}\end{array}$ & $5.9(6.6)$ & $5.8(7.6)$ & $5.9 \quad(7.1)$ \\
\hline $\begin{array}{l}\text { Note: } \mathrm{CAD}=\text { coronary artery disease, } \mathrm{SD}=\text { standard } \\
{ }^{*} \text { Based on participants who reported current daily } \mathrm{s} \\
+\mathrm{CHD} \text { event }=\text { nonfatal myocardial infarction or cor }\end{array}$ & $\begin{array}{l}\text { iation. } \\
\text { king. } \\
\text { ry death. }\end{array}$ & & \\
\hline
\end{tabular}


tion group reported 65.8 more minutes of physical activity each week (95\% confidence interval [CI] 47.0-84.7 $\mathrm{min}$ ) compared with those in the control group (Table 3). At 12 months, participants in the intervention group reported 23.9 more minutes each week ( $95 \%$ CI 3.9-44.0 min)

Table 2: Between- and within-group comparisons for the family heart-health intervention $(n=211)$ and control $(n=215)$ group

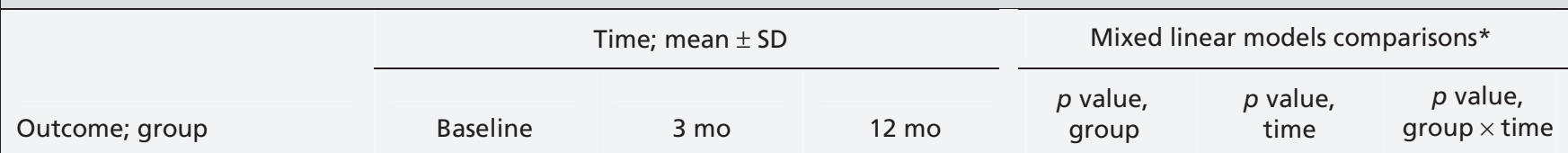

\section{Primary outcomes}

Ratio of total cholesterol to HDL cholesterol

$\begin{array}{lllllll}\text { Heart-health intervention } & 4.12 \pm 1.29 & 4.02 \pm 1.25 & 4.06 \pm 1.31 & 0.6 & 0.9 & 0.6 \\ \text { Control } & 4.22 \pm 1.26 & 4.02 \pm 1.18 & 3.96 \pm 1.09 & & & \end{array}$

Physical activity, min/wk

Heart-health intervention

$91.7 \pm 102.5$

$176.4 \pm 110.9$

$142.5 \pm 122.0<0.001$

0.8

0.03

Control

$88.7 \pm 99.7 \quad 110.6 \pm 115.3 \quad 118.6 \pm 109.1$

Fruits and vegetables, servings/d

$\begin{array}{lllllll}\text { Heart-health intervention } & 6.3 \pm 3.0 & 8.0 \pm 3.3 & 7.4 \pm 3.4 & <0.001 & 0.1 & 0.5 \\ \text { Control } & 6.5 \pm 3.1 & 6.8 \pm 3.2 & 6.6 \pm 3.0 & & & \end{array}$

\section{Secondary outcomes}

Total cholesterol, $\mathrm{mmol} / \mathrm{L}$

Heart-health intervention

$5.13 \pm 0.97$

$4.99 \pm 0.96$

$5.03 \pm 0.98$

0.4

0.9

0.7

Control

$5.18 \pm 1.02$

$4.95 \pm 1.00$

$4.93 \pm 1.01$

HDL cholesterol, mmol/L

Heart-health intervention

$1.33 \pm 0.38$

$1.34 \pm 0.39$

$1.34 \pm 0.41$

0.2

0.9

0.7

Control

$1.30 \pm 0.34$

$1.30 \pm 0.34$

$1.29 \pm 0.30$

LDL cholesterol, $\mathrm{mmol} / \mathrm{L}$

$\begin{array}{lllllll}\text { Heart-health intervention } & 3.22 \pm 0.86 & 3.10 \pm 0.82 & 3.11 \pm 0.82 & 0.5 & 0.8 & 0.6 \\ \text { Control } & 3.28 \pm 0.91 & 3.09 \pm 0.90 & 3.04 \pm 0.92 & & & \end{array}$

Triglycerides, $\mathrm{mmol} / \mathrm{L}$

Heart-health intervention

$1.28 \pm 0.77$

$1.22 \pm 0.66$

$1.35 \pm 0.80$

0.9

0.04

0.8

Control

$1.35 \pm 0.84$

$1.24 \pm 0.57$

$1.34 \pm 0.64$

Glucose, $\mathrm{mmol} / \mathrm{L}$

Heart-health intervention

$5.12 \pm 0.52$

$5.12 \pm 0.50$

$5.16 \pm 0.60$

0.8

0.9

0.3

Control

$5.09 \pm 0.59$

$5.18 \pm 0.54$

$5.13 \pm 0.57$

Systolic blood pressure, $\mathrm{mm} \mathrm{Hg}$

Heart-health intervention

$121.8 \pm 15.3$

$116.4 \pm 14.8$

$118.5 \pm 14.3$

0.5

0.1

0.9

Control

$120.4 \pm 16.9$

$115.8 \pm 14.8$

$117.5 \pm 14.7$

Diastolic blood pressure, $\mathrm{mm} \mathrm{Hg}$

Heart-health intervention

Control

$76.8 \pm 9.0$

$73.8 \pm 8.3$

$75.5 \pm 9.5$

0.8

0.1

0.4

Body mass index

\begin{tabular}{|lllllll} 
Heart-health intervention & $29.2 \pm 5.4$ & $28.2 \pm 4.8$ & $27.9 \pm 4.8$ & 0.006 & 0.4 & 0.9 \\
\hline Control & $29.6 \pm 6.0$ & $29.4 \pm 5.9$ & $29.0 \pm 5.3$ & & & \\
\hline Waist circumference, cm & & & & & 0.3 & 0.9 \\
\hline Heart-health intervention & $96.3 \pm 13.5$ & $93.7 \pm 13.7$ & $92.5 \pm 13.4$ & 0.02 & \\
\hline Control & $97.4 \pm 15.1$ & $96.2 \pm 14.7$ & $95.1 \pm 13.8$ & &
\end{tabular}

Note: $\mathrm{HDL}=$ high-density lipoprotein, $\mathrm{LDL}=$ low-density lipoprotein, SD = standard deviation.

*All analyses include the baseline value of the variable, age and baseline Framingham Risk Score as covariates. 
than control participants. The intervention had a significant effect on body mass index $(p=0.006)$ and waist circumference $(p=0.02)$, but not on levels of other lipids or fasting glucose or blood pressure ( $p>0.05$ for all). Overall, 17.9\% (7/39) of participants who reported smoking at baseline had stopped smoking by the end of the follow-up period. The nonsmoking rate was $30.0 \%$ in the intervention group compared to $5.3 \%$ in the control group (odds ratio 7.7, 95\% CI 0.7-190.9).

Between-group comparisons for the use of antihypertensive, lipid-lowering and smokingcessation medications are shown in Table 4. The use of all medications tended to increase over time. Among participants who had letters sent to their physician with indications for medical care, new antihypertensive medication was started in 7 participants in the intervention group and 9 in the control group. New lipid-lowering medication was started in 4 participants in the intervention group and 7 participants in the control group.

We estimated the incremental cost of providing the intervention to be $\$ 240$ per participant; this assumed 5.3 hours of counselling and contact management time ( $1: 1$ ratio) at $\$ 45 /$ hour.

We conducted an exploratory stratified analyses to examine the effect of the participant's relationship to the index patient (Appendix 1, available at www.cmaj.ca/lookup/suppl/doi:10.1503 /cmaj.130550/-/DC1). The effects of the interven-

Table 3: Pair-wise comparisons of estimated marginal means* at each time for physical activity with significant treatment group by time of follow-up interaction effects

Heart-health intervention - control, min/wk

\begin{tabular}{|lccr|}
\cline { 2 - 4 } Assessment; group & Difference & Standard error & \multicolumn{1}{c|}{$95 \% \mathrm{Cl}$} \\
\hline Baseline & 3.0 & 7.8 & -18.4 to 12.3 \\
\hline 3 mo & 65.8 & 9.6 & 47.0 to 84.7 \\
\hline 12 mo & 23.9 & 10.2 & 3.9 to 44.0 \\
\hline
\end{tabular}

Note: $\mathrm{Cl}=$ confidence interval.

*All analyses include the baseline value of the variable, age and baseline Framingham Risk

Score as covariates. tion on fruit and vegetable consumption and body mass index were consistent across strata. The effect of the intervention on physical activity were greatest among spouses. Among spouses, the intervention also reduced total cholesterol and LDL cholesterol levels. Among offspring, beneficial effects of the intervention were observed for waist circumference, and among siblings the intervention reduced triglyceride levels.

\section{Interpretation}

A heart-health intervention led by a health educator and aimed at family members of patients with CAD did not improve the ratio of total cholesterol to HDL cholesterol among participants, but increased physical activity and fruit and vegetable consumption were reported. Measures of obesity were also improved in the intervention group relative to the control group.

The effects of the heart-health intervention in motivating and enabling behaviour changes are impressive and clinically important. Self-reported changes in physical activity, dietary patterns and smoking cessation were corroborated by improvements in objective measures such as body mass index, waist circumference and expired carbon monoxide. The intervention was likely more effective than control because it incorporated cognitive behavioural strategies, including goal-setting, selfmonitoring, frequent and prolonged contact, feedback and reinforcement, self-efficacy enhancement, problem-solving and relapse prevention. ${ }^{28}$ In contrast, primary care physicians typically use lesseffective techniques for behaviour change, such as advising and providing generic patient handouts. ${ }^{29}$

We sent letters to participants' primary care physicians if blood pressure or lipid levels exceeded critical levels, and we relied on the primary care physicians to initiate or adjust treatments to manage these risk factors. A similar number of letters were sent to physicians in both groups, and it appears that the physicians took steps to address these risk factors.

Table 4: Use of antihypertensive, lipid-lowering and smoking-cessation medications among participants in the heart-health intervention $(n=211)$ and control $(n=215)$ groups at baseline and follow-up

\begin{tabular}{|c|c|c|c|c|c|c|c|c|c|}
\hline \multirow[b]{2}{*}{ Medication, no. (\%) } & \multicolumn{3}{|c|}{ Baseline } & \multicolumn{3}{|c|}{$3 \mathrm{mo}$} & \multicolumn{3}{|c|}{$12 \mathrm{mo}$} \\
\hline & $\begin{array}{l}\text { Heart-health } \\
\text { intervention }\end{array}$ & Control & $p^{*}$ & $\begin{array}{l}\text { Heart-health } \\
\text { intervention }\end{array}$ & Control & $p^{*}$ & $\begin{array}{l}\text { Heart-health } \\
\text { intervention }\end{array}$ & Control & $p^{*}$ \\
\hline Antihypertensive & $67(31.7)$ & $52(24.2)$ & 0.08 & $74(35.1)$ & $58(26.9)$ & 0.07 & $79(37.4)$ & $66(30.6)$ & 0.1 \\
\hline Lipid-lowering & $42(19.9)$ & $51(23.7)$ & 0.3 & $45(21.3)$ & $54(25.1)$ & 0.4 & $47(22.3)$ & $61(28.3)$ & 0.2 \\
\hline Smoking cessationt & $1(5.0)$ & $2(10.5)$ & 0.6 & $7(35.0)$ & $2(10.5)$ & 0.07 & $5(25.0)$ & $3(15.7)$ & 0.5 \\
\hline
\end{tabular}


Three other trials have tested interventions to reduce risk of CAD in family members of patients with CAD. A European randomized controlled trial reported that risk assessment followed by 8 sessions of lifestyle counselling with a nurse and management of risk factors with drugs increased exercise levels, fruit and vegetable consumption and smoking cessation at 52week follow-up among partners of patients with heart disease..$^{30}$ There were no significant effects on waist circumference, blood pressure, total cholesterol, LDL cholesterol or medication use. A randomized controlled trial involving family members who lived with an index patient found that screening for coronary risk factors followed by 5 counselling sessions with a health educator over a 12-month period and progress reports faxed to primary care providers had no effect on the primary outcome (LDL cholesterol at 1 year). ${ }^{31}$ However, there was less reduction in HDL cholesterol, greater improvement in dietary quality and a greater likelihood that participants exercised more than 3 times per week compared with participants in the usual care group. A randomized controlled trial involving siblings of black index patients with premature coronary heart disease $(<60 \mathrm{yr})$ found that care by a nurse practitioner and community health worker at a drop-in centre that included free medication and fitness centre passes made it twice as likely that participants would achieve their LDL cholesterol and blood pressure goals at 1 year. ${ }^{32}$ Our intervention had a greater effect on adiposity and similar effects on physical activity and dietary behaviours compared with these trials. The only trial that has shown effects on lipids and blood pressure enrolled marginalized patients and provided free medication for lowering cholesterol and blood pressure. ${ }^{32}$

During the study period, we found that family members were interested in learning about their personal cardiovascular risk and strategies to mitigate that risk. Hospitalization of a spouse, sibling or parent provided an opportunity to engage family members. Screening for risk factors alone was sufficient to prompt many participants to take actions to reduce their risk, as shown by changes in the control group. Participants in the intervention group were willing to interact frequently with health educators and completed a high percentage of scheduled contacts. These contacts occurred mostly over the phone, thereby reducing patient burden and program costs. High participant engagement and a reasonable cost per participant (\$240) suggest that the intervention is feasible in nontrial settings. The effect of the intervention on health behaviours was greatest in the first 3 months when the frequency of contacts was highest. Additional work is required to identify the optimal schedule for contact. We did not require consent from participants' primary care physicians for trial participation, but we believe that stronger partnerships between counsellors and physicians would enhance the effects on lipid levels and blood pressure. Our intervention may be of most benefit to people at higher risk (e.g., those with diabetes) and should be evaluated in this population.

\section{Strengths and limitations}

Our randomized design was robust with blinded outcome assessment. The $93 \%$ recruitment rate is substantial for a trial involving intensive counselling in primary prevention. Participants in the intervention group completed a high percentage of the counselling sessions (88\%). The risk profile of our sample was similar to Canadian population levels gathered over a similar period. ${ }^{33}$

Our study had some limitations. We recruited a small proportion of people at medium or high risk of CAD; we excluded those with known diabetes or established cardiovascular disease because we assumed that they were already receiving medical care. Our participants were primarily well-educated white people who lived in urban areas. Participants who volunteer for trials may be more motivated than those who do not.

\section{Conclusion}

A family heart-health intervention led by a health educator did not improve the ratio of total cholesterol to HDL cholesterol, but increased physical activity and fruit and vegetable consumption among family members of patients with CAD. This intervention may be an important adjunct to primary care. Effects on cardiovascular events, mortality and health care use should be determined.

\section{References}

1. Bertuzzi M, Negri E, Tavani A, et al. Family history of ischemic heart disease and risk of acute myocardial infarction. Prev Med 2003;37:183-7

2. Hunt SC, Gwinn M, Adams TD. Family history assessment: strategies for prevention of cardiovascular disease. Am J Prev Med 2003;24:136-42

3. Lloyd-Jones DM, Nam BH, D'Agostino RB Sr, et al. Parental cardiovascular disease as a risk factor for cardiovascular disease in middle-aged adults: a prospective study of parents and offspring. JAMA 2004;291:2204-11.

4. McCusker ME, Yoon PW, Gwinn M, et al. Family history of heart disease and cardiovascular disease risk-reducing behaviors. Genet Med 2004;6:153-8.

5. Murabito JM, Pencina MJ, Nam BH, et al. Sibling cardiovascular disease as a risk factor for cardiovascular disease in middleaged adults. JAMA 2005;294:3117-23.

6. Jurj AL, Wen W, Li HL, et al. Spousal correlations for lifestyle factors and selected diseases in Chinese couples. Ann Epidemiol 2006;16:285-91.

7. Lindgren A, Lovkvist H, Hallstrom B, et al. Prevalence of stroke and vascular risk factors among first-degree relatives of stroke patients and control subjects. A prospective consecutive study. Cerebrovasc Dis 2005;20:381-7. 
8. Papamichael C, Zampelas A, Cimponerio A, et al. Wives of patients with acute myocardial infarction are at an increased risk of developing coronary artery disease. J Cardiovasc Risk 2002; 9:49-52.

9. Katzmarzyk PT, Perusse L, Rice T, et al. Familial resemblance for coronary heart disease risk: the HERITAGE Family Study. Ethn Dis 2000;10:138-47.

10. Di Castelnuovo A, Quacquaruccio G, Donati MB, et al. Spousal concordance for major coronary risk factors: a systematic review and meta-analysis. Am J Epidemiol 2009;169:1-8

11. Lee KE, Klein BE, Klein R. Familial aggregation of components of the multiple metabolic syndrome in the Framingham Heart and Offspring Cohorts: Genetic Analysis Workshop Problem 1. BMC Genet 2003;4 Suppl 1:S94.

12. Martínez Vizcaíno V, Salcedo Aguilar F, Franquelo Gutierrez R, et al. Familial aggregation of cardiovascular disease risk factors: the Cuenca Study. Prev Med 1999;28:131-7.

13. Genest J, McPherson R, Frohlich J, et al. 2009 Canadian Cardiovascular Society/Canadian guidelines for the diagnosis and treatment of dyslipidemia and prevention of cardiovascular disease in the adult - 2009 recommendations. Can J Cardiol 2009;25: 567-79.

14. Lloyd-Jones DM, Hong Y, Labarthe D, et al. Defining and setting national goals for cardiovascular health promotion and disease reduction: the American Heart Association's strategic Impact Goal through 2020 and beyond. Circulation 2010;121: 586-613.

15. Perk J, De Backer G, Gohlke H, et al. European Guidelines on cardiovascular disease prevention in clinical practice (version 2012). The Fifth Joint Task Force of the European Society of Cardiology and Other Societies on Cardiovascular Disease Prevention in Clinical Practice (constituted by representatives of nine societies and by invited experts). Eur Heart J 2012;33:1635-701.

16. De Sutter J, De Bacquer D, Kotseva K, et al. Screening of family members of patients with premature coronary heart disease; results from the EUROASPIRE II family survey. Eur Heart $J$ 2003;24:249-57.

17. Swanson JR, Pearson TA. Screening family members at high risk for coronary disease. Why isn't it done? Am J Prev Med 2001; 20:50-5.

18. Velicer WF, Prochaska JO, Rossi JS, et al. Assessing outcome in smoking cessation studies. Psychol Bull 1992;111:23-41.

19. Boucher B, Cotterchio M, Kreiger N, et al. Validity and reliability of the Block98 food-frequency questionnaire in a sample of Canadian women. Public Health Nutr 2006;9:84-93.

20. Reid RD, Morrin LI, Higginson LA, et al. Motivational counselling for physical activity in patients with coronary artery disease not participating in cardiac rehabilitation. Eur J Prev Cardiol 2012;19:161-6

21. Campbell NR, Khan NA, Hill MD, et al. 2009 Canadian Hypertension Education Program recommendations: the scientific summary — an annual update. Can J Cardiol 2009;25:271-7.

22. Canadian Diabetes Association Clinical Practice Guidelines Expert Committee. Canadian Diabetes Association 2008 clinical practice guidelines for the prevention and management of diabetes in Canada. Can J Diabetes 2008;32 Suppl 1:S1-201.

23. Fiore MC, Jaén CR, Baker TB, et al. Treating tobacco use and dependence: 2008 update [clinical practice guideline]. Rockville (MD): US Department of Health and Human Services, Public Health Service; 2008.

24. Canada's physical activity guide to healthy active living. Ottawa $(\mathrm{ON})$ : Health Canada and the Canadian Society for Exercise Physiology; 1998. Available: publications.gc.ca/collections /Collection/H39-429-1998-1E.pdf (accessed 2007 July 4).

25. Majumdar S, Johnson JA, Bowker SL, et al. A Canadian consensus for the standardized evaluation of quality improvement interventions in type 2 diabetes. Can J Diabetes 2005;29:220-9.

26. Wisløff U, Nilsen TI, Droyvold WB, et al. A single weekly bout of exercise may reduce cardiovascular mortality: how little pain for cardiac gain? 'The HUNT study, Norway'. Eur J Cardiovasc Prev Rehabil 2006;13:798-804.

27. Bazzano LA, He J, Ogden LG, et al. Fruit and vegetable intake and risk of cardiovascular disease in US adults: the first National Health and Nutrition Examination Survey Epidemiologic Follow-up Study. Am J Clin Nutr 2002;76:93-9.

28. Artinian NT, Fletcher GF, Mozaffarian D, et al. Interventions to promote physical activity and dietary lifestyle changes for cardiovascular risk factor reduction in adults: a scientific statement from the American Heart Association. Circulation 2010;122: 406-41.

29. Harris SB, Petrella RJ, Lambert-Lanning A, et al. Lifestyle management for type 2 diabetes. Are family physicians ready and willing? Can Fam Physician 2004;50:1235-43.

30. Wood DA, Kotseva K, Connolly S, et al. Nurse-coordinated multidisciplinary, family-based cardiovascular disease prevention programme (EUROACTION) for patients with coronary heart disease and asymptomatic individuals at high risk of cardiovascular disease: a paired, cluster-randomised controlled trial. Lancet 2008;371:1999-2012.

31. Mosca L, Mochari H, Liao M, et al. A novel family-based intervention trial to improve heart health: FIT Heart: results of a randomized controlled trial. Circ Cardiovasc Qual Outcomes 2008; 1:98-106.

32. Becker DM, Yanek LR, Johnson WR Jr, et al. Impact of a community-based multiple risk factor intervention on cardiovascular risk in black families with a history of premature coronary disease. Circulation 2005;111:1298-304.

33. Lee DS, Chiu M, Manuel DG, et al. Trends in risk factors for cardiovascular disease in Canada: temporal, socio-demographic and geographic factors. CMAJ 2009;181:E55-66.

Affiliations: Division of Prevention and Rehabilitation (Reid, McDonnell, Riley, Mark, Papadakis, O'Farrell, Slovinec D'Angelo, Pipe), and the Cardiovascular Research Methods Centre (Wells), University of Ottawa Heart Institute, Ottawa, Ont.; Preventive Cardiology (Mosca, MochariGreenberger), Columbia University Medical Center, New York; the North Bay Parry Sound District Health Unit (Beaton), North Bay, Ont.; Department of Medicine (Blanchard), Dalhousie University, Halifax, NS

Contributors: Robert Reid, Lisa McDonnell, Sophia Papadakis, Monika Slovinec D'Angelo and Andrew Pipe helped conceive and design the study and acquired and analyzed data. Dana Riley, Amy Mark and Lori Mosca analyzed data. Louise Beaton helped conceive and design the study. Chris Blanchard, Heidi Mochari-Greenberger and George Wells helped conceive and design the study and analyze data. Patricia O'Farrell helped conceive and design the study and acquired data. All authors revised the article for important intellectual content and approved the final version submitted for publication.

Funding: This research was funded by a grant from the Heart and Stroke Foundation of Ontario (grant no. 6142). The study sponsor had no role in the design of the study, the collection, analysis or interpretation of data, the writing of the report or the decision to submit the article for publication.

Acknowledgements: The authors thank Tania Bennett, Nadine Elias, Lorraine Montoya, Isabelle Lalonde, Jessica Nooyen, Sue Perron and Ashley Armstrong for their assistance with recruitment, counselling and data collection, and Eftyhia Helis for assistance with manuscript preparation. 